\title{
revisión
}

\section{Mejor convencer entreteniendo: comunicación para la salud y persuasión narrativa}

\author{
Juan José Igartua \\ (Salamanca, España) \\ Universidad de Salamanca, Facultad de Ciencias Sociales
}

\footnotetext{
Palabras clave

educación-entretenimiento persuasión narrativa modelo de transporte narrativo modelo de probabilidad de elaboración extendido identificación con los personajes.
}

\begin{abstract}
Resumen
La meta de las intervenciones de comunicación para la salud es cambiar comportamientos, actitudes, creencias, normas sociales en determinados públicos o segmentos sociales, con objeto de aumentar la calidad de vida de las personas y mejorar la salud pública en una determinada sociedad o cultura. Gran parte de las intervenciones en comunicación para la salud se apoya en el concepto de "campaña" y se asienta en el marketing social como modelo de gestión. Sin embargo, uno de los campos más prometedores en comunicación para la salud es aquel que ha venido en denominarse educación-entretenimiento. Las estrategias basadas en la educación-entretenimiento incluyen mensajes que son atractivos para sus audiencias, tienen un fuerte componente emocional y una estructura narrativa clara, y suelen enganchar a las audiencias al igual que cualquier otro contenido de entretenimiento de carácter comercial. En el presente artículo se hace una revisión de la aproximación educación-entretenimiento: sus aspectos definitorios, sus orígenes históricos, los campos de aplicación, así como los modelos teóricos que explican el éxito de tales intervenciones, los cuales se apoyan en la investigación sobre persuasión narrativa, es decir, el uso de las narraciones de ficción para inducir de manera incidental cambios en las actitudes de las personas.
\end{abstract}




\section{It's better to convince entertaining: Health communication and narrative persuasion}

\begin{tabular}{c}
\hline Keywords \\
\hline entertainment-education \\
narrative persuasion \\
transportation-imagery \\
model \\
extended elaboration like- \\
lihood model \\
identification with charac- \\
ters.
\end{tabular}

ters.

\begin{abstract}
The goal of health communication interventions is to change behaviors, attitudes, beliefs, social norms in certain public or social segments in order to increase people's quality of life and improve public health in a particular society or culture. Many health communication interventions rely on the "campaign" concept and are based on the management model of social marketing. However, one of the most promising fields in health communication is one that has come to be called entertainment-education. Strategies based on entertainment-education include messages that appeal to their audiences, have a strong emotional component and clear narrative structure, and often engage the audience like any other commercial entertainment content. In this article we review the entertainment-education approach: its defining aspects, its historical origins, as well as the theoretical models that explain the success of such interventions, which are based on the research of narrative persuasion: the use of fictional narrations to induce changes in people's attitudes.
\end{abstract}

\section{Cómo citar el artículo}

Igartua, J. J. (2011). Mejor convencer entreteniendo: comunicación para la salud y persuasión narrativa. Revista de Comunicación y Salud, 1(1), pp. 73-87.

DOI: http://doi.org/10.35669/revistadecomunicacionysalud.2011.1(1).73-87

¿Cómo convencer a las personas para que modifiquen sus comportamientos de riesgo, desde dejar de fumar hasta reducir el consumo de alcohol? ¿Qué estrategias de comunicación son más eficaces para lograr que las personas comiencen a desarrollar conductas positivas de salud (como hacer ejercicio físico con regularidad o incluir fruta y verdura en la dieta diaria)? Ambas preguntas se relacionan directamente con el tipo de actividades que se desarrollan en el campo de la comunicación para la salud, cuya meta es cambiar comportamientos, actitudes, creencias, normas sociales en determinados públicos o segmentos sociales, con objeto de aumentar la calidad de vida de las personas y mejorar la salud pública en una determinada sociedad o cultura. Dicha disciplina se asienta en dos pilares teóricos: en la investigación sobre el cambio conductual (por ejemplo, el Modelo de Creencias de Salud) y en la investigación sobre los usos, procesos y efectos de la comunicación mediática (Fishbein y Cappella, 2006; 
Viswanath, Wallington y Blake, 2010). Ahora bien, las intervenciones en este campo son muy variadas y se hayan sujetas a cambios directamente relacionados con el avance teórico y las constantes innovaciones tecnológicas que tienen lugar en los procesos de comunicación mediática.

Gran parte de las intervenciones en comunicación para la salud se apoya en el concepto de "campaña" (de corte publicitario) y se asienta en el marketing social como modelo de gestión (Rice y Atkin, 2009). En este contexto, los modelos o teorías de la persuasión son de gran ayuda (como el Modelo de Probabilidad de Elaboración de Petty y Cacioppo, 1986), al igual que lo son los modelos psico-sociales que explican el impacto de las actitudes en la intención de conducta (por ejemplo, la Teoría de la Acción Razonada de Ajzen y Fishbein, 1980). Sin embargo, uno de los campos más prometedores en comunicación para la salud es aquel que ha venido en denominarse educación-entretenimiento (Singhal, Cody, Rogers y Sabido, 2004; Singhal y Rogers, 1999). Frente a las intervenciones basadas en las campañas de información, que incluyen mensajes breves, de carácter abiertamente persuasivo y que, por ello, pueden provocar un fuerte rechazo y reactancia (entre otras razones, porque interfieren en el proceso de recepción de mensajes que sí han sido seleccionados por las audiencias para su visionado), las estrategias basadas en la educación-entretenimiento incluyen mensajes que son atractivos para sus audiencias, tienen un fuerte componente emocional y una estructura narrativa clara, y suelen enganchar a las audiencias al igual que cualquier otro contenido de entretenimiento de carácter comercial (Moyer-Gusé, 2008; Slater y Rouner, 2002).

En el presente artículo se hace una revisión de la aproximación educación-entretenimiento (entertainment-education): sus aspectos definitorios, sus orígenes históricos, los campos de aplicación, así como los modelos teóricos que explican el éxito de tales intervenciones que, como se verá, se apoyan en la investigación sobre persuasión narrativa, es decir, el uso de las narraciones de ficción para inducir de manera incidental cambios en las actitudes de las personas (Green, Strange y Brock, 2002; Igartua, 2007; Igartua, Cheng y Lopes, 2003). A diferencia de los mensajes persuasivos utilizados en las campañas de información, las narraciones utilizadas en educación-entretenimiento: a) se refieren a sucesos o acontecimientos, en vez de incluir argumentos de manera explícita o un listado con información exhaustiva; b) se basan en personajes, y no en fuentes externas que entregan información o advierten de algún peligro; c) se consumen para entretenerse o divertirse, aunque ello no impide que se produzca un efecto educativo mediante aprendizaje incidental; d) presentan una estructura muy definida (con un planteamiento, nudo o conflicto y desenlace o resolución) y las distintas acciones que contienen se relacionan directamente en una cadena causal, y este atributo las distingue también de las campañas de carácter informativo, en las que se fija o lista una serie de proposiciones sin una conexión causal evidente (Green, 2006).

\section{Preparados para las historias: las narraciones nos enganchan}

A lo largo de la historia las narraciones (sobre hechos verídicos o de ficción) han sido utilizadas para compartir información, cambiar creencias o inspirar comportamientos (Green y Brock, 2005). Hasta tal punto que se puede afirmar que el rasgo más distintivo del ser humano como especie es su capacidad de contar historias (Morgan, 2010). De este modo, la narración (storytelling) parece ser una forma básica para que las personas comprendan el mundo, y los seres humanos 
pueden ser definidos como homo narrans (Petraglia, 2007: 496). Bruner (1988) llega incluso a plantear que existen dos modalidades de pensamiento, dos modalidades de funcionamiento cognitivo, que difieren en sus procedimientos de verificación, pero ambas tienen poder de convencimiento. Una de las modalidades la define como paradigmática o lógico-científica: se ocupa del estudio de las causas y emplea procedimientos para asegurar referencias verificables y para verificar la verdad empírica. El segundo modelo, de pensamiento narrativo, se ocupa de las intenciones y acciones humanas, produce relatos, obras dramáticas o crónicas históricas creíbles (aunque no necesariamente verdaderas).

La narración constituye un elemento omnipresente en la experiencia de las audiencias ante contenidos de entretenimiento mediático (Shanahan y Morgan, 1999). Las obras de teatro, las películas o las series televisivas, todas ellas cuentan historias. $Y$ ante ellas, las personas experimentan fuertes reacciones emocionales, similares a las que se experimenta en la vida cotidiana ante sucesos vividos en primera persona (Tan, 1996). La "ley de la realidad aparente", postulada por Frijda (1988), advierte que "las emociones son generadas por acontecimientos evaluados como reales, y su intensidad es proporcional al grado en que sea así" (p. 352). Así, las narraciones (escritas o audiovisuales) logran inducir una ilusión de realidad: y, por eso, los largometrajes que abordan dramas como el holocausto judío, los conflictos bélicos, la explotación del ser humano y el racismo o la discapacidad pueden emocionar a los espectadores y provocar un impacto afectivo (Igartua, 2010; Igartua, Acosta y Frutos, 2009; Igartua y Muñiz, 2008).

Pero el consumo de narraciones ejerce efectos significativos más allá del puro entretenimiento, la diversión y el impacto afectivo. Dado que el ser humano tiene capacidad para aprender por observación, para comprender su mundo (físico o social) no necesita experimentarlo directamente. Ello supone que una gran parte de los conocimientos que adquiere una persona a lo largo de su vida no los obtiene a través de la experiencia directa, sino a través de las historias que escucha e interioriza. En este sentido, existe evidencia empírica de que las audiencias atienden y recuerdan la información sobre salud que se incorpora, de manera incidental, en largometrajes de ficción y series de televisión. Snyder y Rouse (1995) encontraron que la exposición a programas de entretenimiento (como películas y series de televisión) que trataban el tema del sida estaba relacionada con el aumento de las opiniones de riesgo personal de sufrir esta enfermedad. Lapinski y Nwulu (2008) comprobaron que el visionado de una película de ficción que se centraba en el estigma social hacia las personas portadoras de VIH incrementaba la percepción de severidad del VIH y reducía la atribución de culpabilidad hacia las personas portadoras de VIH (en comparación con un grupo control no expuesto a la película). Igualmente, se ha podido comprobar que la exposición a un largometraje de ficción que entregaba un mensaje negativo hacia la industria tabaquera, provocaba actitudes más negativas hacia ella e incluso inducía un menor deseo por seguir fumando en el futuro (Dixon, Hill, Borland y Paxton, 2001). Finalmente, Morgan, Movius y Cody (2009) observaron que incluir historias dramáticas sobre la donación de órganos en series televisivas de éxito facilitaba la adquisición de conocimientos sobre este tema, e incluso influía en la intención de convertirse en donante de órganos, especialmente si se producía una alta implicación emocional con la serie.

Por tanto, la narración no sólo constituye un elemento central de la cultura humana, sino que sustituye o suple a la experiencia directa como fuente de socialización, posee la capacidad de enganchar o provocar una alta implicación emocional en el público, de provocar fuertes 
reacciones emocionales y, finalmente, permite el aprendizaje incidental de actitudes, creencias y comportamientos. Este potencial de la narración está siendo utilizado con eficacia en las intervenciones de educación-entretenimiento en todo el mundo, llegándose a definir este tipo de actuaciones como intervenciones narrativas (Petraglia, 2007). Pero antes de revisar este tipo de actuaciones y analizar su eficacia, conviene definir este campo y trazar sus coordenadas históricas.

Tabla 1.- Investigaciones sobre el impacto de intervenciones de educación-entretenimiento (selección de estudios)

\begin{tabular}{|c|c|}
\hline Sida & $\begin{array}{l}\text { Goldstein, S., Usdin, S., Scheepers, E. y Japhet, G. (2005). Communicating HIV and AIDS, what } \\
\text { works? A report on the impact evaluation of Soul City's fourth series. Journal of Health Communication, } \\
\text { 10, 465-483. }\end{array}$ \\
\hline Cáncer & $\begin{array}{l}\text { Hether, H., J., Huang, G. C., Beck, V., Murphy, S. T., Valente, T. W. (2008). Entertainment-education } \\
\text { in a media-saturated environment: examining the impact of single and multiple exposures to breast } \\
\text { cancer storylines on two popular medical dramas. Journal of Health Communication, 13, 808-823. }\end{array}$ \\
\hline Sida & $\begin{array}{l}\text { Lapinski, M. K. y Nwulu, P. (2008). Can a short film impact hiv-related risk and stigma perceptions? } \\
\text { Results from an experiment in Abuja, Nigeria. Health Communication, 23, 403-412. }\end{array}$ \\
\hline Sida & $\begin{array}{l}\text { Lemieux, A. F., Fisher, J. D. y Pratto, F. (2008). A music-based hiv prevention intervention for urban } \\
\text { adolescents. Health Psychology, 27(3), 349-357. }\end{array}$ \\
\hline $\begin{array}{l}\text { Embarazos no } \\
\text { deseados }\end{array}$ & $\begin{array}{l}\text { Moyer-Gusé, E. y Nabi, R. L. (2010). Explaining the effects of narrative in an entertainment television } \\
\text { program: overcoming resistance to persuasion. Human Communication Research, 36(1), 26-52. }\end{array}$ \\
\hline Sida & $\begin{array}{l}\text { Vaughan, P. W., Rogers, E. M., Singhal, A. \& Swalehe, R. M. (2000). Entertainment-education and } \\
\text { HIVIAIDS prevention: a field experiment in Tanzania. Journal of Health Communication, 5, 81-100. }\end{array}$ \\
\hline Cáncer & $\begin{array}{l}\text { Wilkin, H. A., Valente, T. W., Murphy, S., Cody, M. J., Huang, G. \& Beck, V. (2007). Does entertain- } \\
\text { ment-education work with Latinos in the United States? Identification and effects of a telenovela breast } \\
\text { cancer storyline. Journal of Health Communication, 12(5), 455-469. }\end{array}$ \\
\hline
\end{tabular}

Fuente: elaboración propia 


\section{La aproximación educación-entretenimiento: coordenadas históricas}

La aproximación educación-entretenimiento se ha convertido en los últimos años en una estrategia de amplia utilización y eficacia para hacer frente a problemas sociales y sanitarios (Singhal y Rogers, 1999; Singhal et al., 2004). Básicamente consiste en insertar un contenido educativo en mensajes destinados al entretenimiento (telenovelas, seriales radiofónicos, series de televisión, películas, vídeos musicales, cómics, juegos, canciones, videojuegos, etc.) con el fin de incrementar el conocimiento sobre el tema, generar actitudes favorables y provocar cambios comportamentales y sociales.

El pionero de este tipo de intervenciones fue Miguel Sabido a partir de constatar el enorme éxito de las telenovelas en Latinoamérica (Poindexter, 2004) y, en particular, tras comprobar el impacto social de la telenovela Simplemente María (emitida en Perú entre 1969 y 1971, y producida por Vlado Radovich para Panamericana Televisión en 1969). Dicha novela, que narra las desventuras de una joven que emigra a la gran ciudad para labrarse un futuro, remitía al sueño de la movilidad social ascendente y de la emigración exitosa. Esta telenovela no solo marcó altas cotas de audiencias (rating medio del $85 \%$ en los 448 capítulos emitidos) sino que impulsó procesos y cambios sociales importantes. Así, por ejemplo, se comprobó que tras su emisión aumentaron las matrículas en educación para adultos entre las jóvenes y también la venta de máquinas de coser de la marca Singer (la que utilizaba la protagonista). A partir de la constatación de estos efectos provocados por una obra de ficción televisiva, Miguel Sabido elaboró una nueva metodología para el desarrollo o producción de telenovelas con mensaje social. De esta forma, inspirado en el impacto de Simplemente María, y apoyándose en la Teoría Socio-Cognitiva de Albert Bandura, Miguel Sabido creó siete telenovelas (desde 1975 hasta 1982) aplicando la aproximación educación-entretenimiento (Singhal y Rogers, 2002).

En la actualidad se han desarrollado más de 200 intervenciones basadas en la estrategia de educación-entretenimiento, ejecutadas en cerca de 50 países de África, Asia, Europa y América, para hacer frente a problemas sociales como la planificación familiar, la discriminación por razón de género, la violencia de género, el sida, la alfabetización de adultos, el consumo de drogas, el cáncer, entre otros muchos temas (Greenberg, Salmon, Patel, Beck y Cole, 2004). Entre ellas cabe citar las intervenciones diseñadas e implementadas por la organización sudafricana Soul City (http://www.soulcity.org.za) y las experiencias de Tanzania, en donde se han desarrollado productos mediáticos eficaces, por ejemplo, para la prevención del sida o la violencia de género (Usdin, Singhal, Shongwe, Goldstein y Shabalala, 2004). Una característica básica de estas producciones audiovisuales es la implicación y trabajo colaborativo entre organizaciones gubernamentales, organizaciones no gubernamentales, medios de comunicación, guionistas e investigadores, lo que permite diseñar intervenciones contemplando una fase de investigación formativa (para desarrollar un cuidado proceso de diseño de personajes y tramas narrativas) y la evaluación sumativa con técnicas cualitativas y cuantitativas para conocer el impacto real de dichas intervenciones (Sood, Menard y Witte, 2004). 
Tabla 2. Programas de educación-entretenimiento supervisados por el Centro para los Programas de Comunicación de la Universidad Johns Hopkins (desde 1986 hasta 2002, por tipo y región)

\begin{tabular}{|l|c|c|c|c|c|c|}
\hline \multicolumn{7}{|c|}{ Series dramáticas } \\
\hline Región & Radio & Televisión & $\begin{array}{l}\text { Películas y } \\
\text { vídeos }\end{array}$ & Canciones & $\begin{array}{c}\text { Programas de } \\
\text { variedades }\end{array}$ & $\begin{array}{c}\text { Aprendizaje a } \\
\text { distancia }\end{array}$ \\
\hline África & 18 & 9 & 14 & 8 & 8 & 4 \\
\hline Asia & 3 & 7 & 14 & 3 & 1 & 3 \\
\hline América Latina & 3 & 3 & 2 & 7 & 3 & 1 \\
\hline Cercano Oriente & 0 & 4 & 5 & 0 & 1 & 0 \\
\hline Europa/Eurasia & 0 & 0 & 3 & 0 & 0 & 0 \\
\hline Total & 24 & 23 & 38 & 18 & 13 & 8 \\
\hline
\end{tabular}

Fuente: Piotrow y de Fossard (2004: 41)

\section{Educación-entretenimiento y persuasión narrativa}

Una buena parte de la investigación sobre la eficacia de las intervenciones de educaciónentretenimiento se ha basado en la Teoría Socio-Cognitiva (Bandura, 2004; Sabido, 2004). Sin embargo, Slater y Rouner (2002) consideran que esta aproximación teórica no aporta una explicación completa. La teoría de Bandura se centra en exclusividad en los procesos de aprendizaje de nuevos comportamientos por medio de la observación de modelos simbólicos (los personajes de una ficción). En cambio, es necesario destacar que las intervenciones de educación-entretenimiento suelen provocar efectos indirectos a otros niveles, en particular en las actitudes y en las creencias, que suelen preceder los cambios conductuales. Además, este tipo de efectos persuasivos habitualmente son de mayor envergadura (desde un punto de vista estadístico) que los efectos en los comportamientos. De este modo, ambos autores señalan que cualquier análisis sobre los mecanismos de influencia de los contenidos de educaciónentretenimiento deberá tener en consideración y analizar cómo se produce la persuasión.

Y es en este contexto donde la investigación sobre persuasión narrativa se ha fusionado con las intervenciones de educación-entretenimiento. Este nuevo campo de estudio se diferencia de la clásica investigación sobre persuasión retórica (Petty, Briñol y Priester, 2009). Así, el énfasis recae en analizar cómo la exposición a narraciones de ficción diseñadas para entretener o provocar diversión, pero que contienen mensajes prosociales (implícitos) sobre diversos temas o actores sociales, puede provocar también efectos persuasivos (Green y Brock, 2005). Con todo, el nivel de desarrollo teórico para comprender los mecanismos y procesos implicados 
en la persuasión narrativa es muy reciente (Dal Cin, Zanna y Fong, 2002; Moyer-Gusé, 2008). En la actualidad gran parte de la investigación sobre persuasión narrativa se está desarrollando teniendo como referencia dos modelos teóricos: el Modelo de Probabilidad de Elaboración Extendido (Extended Elaboration Likelihood Model) (Slater, 2002; Slater y Rouner, 2002) y el Modelo de Transporte Narrativo (Transportation-Imagery Model) (Green y Brock, 2000, 2002; Green, Garst y Brock, 2004).

\subsection{Modelo de Probabilidad de Elaboración Extendido (E-ELM)}

EI E-ELM ha sido propuesto por Slater y Rouner (2002) para comprender el impacto persuasivo de las narraciones de ficción empleadas en las intervenciones de educación-entretenimiento. Parten de constatar que no se procesan del mismo modo los mensajes persuasivos y los contenidos de educación-entretenimiento, dado que las metas y motivaciones son muy diferentes. Así, frente a un mensaje persuasivo tradicional (como un anuncio en una campaña de información) una motivación o meta de procesamiento básica es desarrollar actitudes correctas con respecto a un tema concreto. En este contexto, el nivel de implicación con el tema abordado por el anuncio (issue involvement) juega un papel central para comprender cómo se producirá el proceso persuasivo. Si el mensaje se relaciona con un tópico relevante para la persona, se producirá un procesamiento sistemático, intenso y cuidadoso de sus argumentos (vía ruta central). Sin embargo, cuando el mensaje se centra en un tópico de baja relevancia, el individuo no desarrollará un procesamiento tan cuidadoso o sistemático (ruta periférica).

Con todo, en ambos casos se puede producir un impacto en las actitudes aunque el mecanismo que lo explique puede ser distinto. Por el contrario, las motivaciones y metas de las personas que se exponen a contenidos de educación-entretenimiento, que también contienen un mensaje persuasivo (aunque no presentado en forma de argumentos), presumiblemente son muy diferentes y se basan, por lo general, en la búsqueda de entretenimiento y diversión, y no en la posibilidad de desarrollar actitudes más o menos correctas con respecto a un tópico particular. Este tipo de producciones pretende, ante todo, atraer la atención de las audiencias e inducir entretenimiento, por lo que deben contar con cierta calidad narrativa y atractivo dramático para implicar y provocar disfrute en primer lugar, ya que si el intento persuasivo fuera muy evidente se provocaría rechazo o reactancia, reduciéndose su eficacia (véase Moyer-Gusé y Nabi, 2010).

Slater y Rouner (2002) utilizan el concepto de absorción para reconocer que la principal propiedad que debe tener una obra de ficción, que sea eficaz como medio de persuasión incidental, es su potencial para que los sujetos se puedan "enganchar" o implicar con facilidad. A juicio de estos autores la identificación con los personajes también cumple un papel fundamental para explicar el grado de implicación con una obra de ficción de educación-entretenimiento (Slater, 2002). De este modo, el modelo propuesto por Slater y Rouner (2002) plantea que los dos mecanismos principales para explicar los efectos de persuasión incidental de los contenidos de ficción de educación-entretenimiento son la absorción y la identificación con los personajes: "el impacto persuasivo de los subtextos incorporados en una narración dependerá del grado de absorción o 'enganche' con dicha narración” (p. 178). Igualmente se plantea que la identificación con los personajes es el resultado de la absorción provocado por la obra de ficción. De este 
modo, se establece una clara conexión entre ambos conceptos pero asumiendo que la absorción precede a la identificación con los personajes. Incluso, se llega a mantener que una narración de ficción podría provocar un estado de alta absorción aunque no se establecieran lazos afectivos y reacciones empáticas con los personajes de la misma.

A diferencia de lo planteado en el modelo de probabilidad de elaboración de Petty y Cacioppo (1986), este modelo extendido no concede importancia a la elaboración cognitiva y tampoco plantea la existencia de dos rutas de persuasión. En primer lugar, la elaboración cognitiva no juega un lugar destacado al asumirse que los contenidos de ficción que provocan implicación tienden a cortocircuitar o impedir los procesos de contra-argumentación: las personas implicadas durante la ficción, es decir, que se identifican con los personajes y experimentan estados de alta absorción, son incapaces de generar críticas y contra-argumentos con respecto al contenido persuasivo del mensaje. Es decir, se plantea que existe una relación negativa entre el grado de inmersión y la contra-argumentación cognitiva: si las personas enfrentadas a una narración de ficción estuvieran constantemente efectuando críticas hacia el texto implícito o el mensaje cultivado por la narración, sería improbable que se produjera un estado de alta inmersión o absorción. En cambio, una persona que se encuentra totalmente implicada con el desarrollo de la acción de la narración de ficción y sus personajes probablemente evitará reflexionar de manera crítica (y se verá incapacitado para ello, además). Por ello, Slater y Rouner (2002) consideran que la capacidad persuasiva de la narración de ficción se explica fundamentalmente por la potencialidad de ésta para bloquear los "pensamientos negativos" o críticos con respecto a los argumentos implícitos o cultivados (el subtexto, se podría decir).

Una segunda diferencia del modelo extendido con respecto al modelo de Petty y Cacioppo (1986) es no plantear la existencia de dos rutas de persuasión. De este modo, Slater y Rouner (2002) indican que la absorción durante la exposición a una obra de ficción es el mecanismo responsable del impacto persuasivo incidental: a mayor absorción, mayor impacto persuasivo independientemente del grado de implicación previa con el tema de la narración, dado que la inmersión impide un examen crítico y reflexivo del mensaje. Además, el tipo de procesamiento que induce la absorción es distinto del que se produce ante un mensaje explícitamente persuasivo. Frente a una narración de ficción la absorción provoca un estado de alta implicación afectiva gracias al proceso de identificación con los personajes, siendo menos relevante la activación de un proceso de reflexión o contra-argumentación que, en todo caso, impediría una adecuada inmersión en la ficción. De este modo, la absorción puede inducir una mayor implicación con la ficción, pero dicha implicación es menos analítica y más emocional que cognitiva.

\subsection{Modelo de Transporte Narrativo}

Oatley (2002) ha señalado que cualquier texto de ficción actúa como una especie de vehículo que permite al lector realizar un viaje simbólico a otros mundos; un vehículo que se elige libremente porque se desea ser transportado a otro lugar. Además, identifica la experiencia de la lectura de la ficción con un estado similar a la hipnosis: el lector es transformado o transportado por lo que lee al sufrir una especie de estado de trance cuando entra en contacto con la lectura del relato. Esta idea enlaza con una experiencia cotidiana entre los lectores de obras literarias que llegan a experimentar el sentimiento de "estar perdidos en el relato" cuando se enfrentan 
a la lectura de una obra de ficción (Nell, 1988). Se puede afirmar que el punto de partida del Modelo del Transporte Narrativo, propuesto por Green y Brock $(2000,2002)$, guarda mucha relación con el planteamiento de Oatley (2002). Sin embargo, los orígenes de dicha teoría se remontan al trabajo de Gerrig (1993) titulado Experiencing narratives worlds. En dicho trabajo el autor describe el proceso de transporte narrativo (transportation) de la siguiente forma:

"Alguien (el viajero) es transportado, gracias a algún medio de transporte, y como resultado de la ejecución de ciertas acciones. El viajero se aleja de su mundo de origen, por lo que muchos aspectos de dicho mundo permanecerán inaccesibles durante la lectura del relato. Sin embargo, cuando el viajero retorna al mundo de origen, algo necesariamente ha cambiado como consecuencia de este viaje" (pp. 10-11).

Esta metáfora sobre la experiencia de la lectura plantea que los contenidos narrativos inducen estados de inmersión, absorción o transporte narrativo, es decir, permiten al espectador un viaje simbólico a otros mundos. Green y Brock $(2000,2002)$ afirman que dicho proceso de inmersión no sólo explica el disfrute o placer estético que experimenta el lector, sino que además es responsable del impacto que provoca la narración de ficción en las actitudes y creencias sobre el mundo social: cuando una persona viaja a otro lugar (aunque sea simbólicamente leyendo una novela o viendo una película) algo en su interior se modifica y provoca consecuencias cognitivas palpables en la percepción del mundo social. En este sentido, sentirse transportado a otros mundos y abandonar el propio no es un viaje vacío ya que cuando el espectador vuelve del mundo imaginario de la ficción a la vida real es probable que regrese con opiniones o creencias basadas en lo que previamente, de alguna manera, ha experimentado durante dicho viaje (Green, Brock y Kaufman, 2004; Green, Garst y Brock, 2004). De este modo, el Modelo del Transporte Narrativo se convierte en una explicación de los procesos de persuasión de la narración de ficción, es decir, de la influencia de los de productos de la imaginación.

Según Green y Brock (2002) el fenómeno denominado transporte narrativo es un estado de inmersión o absorción en el texto que se vincula con tres subprocesos psicológicos: la focalización de la atención en el relato, la activación de imágenes mentales y la implicación emocional. En primer lugar, un sujeto transportado en un relato de ficción experimenta una pérdida de atención con respecto a la realidad física inmediata y, simultáneamente, una focalización de la atención en la narración y en la realidad que se describe. Así, algunos aspectos del "mundo de origen" se vuelven inaccesibles, de ahí que se utilice en ocasiones el concepto de inmersión. A nivel físico el espectador inmerso en una narración de ficción no será consciente de los cambios que se producen en su entorno cercano porque sus recursos atencionales están concentrados en el relato. A nivel psicológico, esta pérdida de atención del mundo cercano, en beneficio del mundo del relato, significará también que puede producirse un cierto distanciamiento de la realidad personal o subjetiva y, por ello, constituir un medio de distracción para escapar del estrés y de las preocupaciones personales (Green, Brock y Kaufman, 2004).

Una segunda dimensión del concepto de transporte narrativo está relacionada con la activación de la imaginación y la inducción de imágenes mentales de alta vivacidad. Las imágenes mentales son un tipo particular de representación cognitiva de un estímulo, cuya formación se explica por la activación del sistema sensorial (Green y Brock, 2002). En este sentido, cuando 
una persona se encuentra en un estado de inmersión por la exposición a un relato de ficción, será consciente de que se forman en su mente imágenes muy claras y vívidas sobre los diferentes elementos de la historia narrada (los personajes, los escenarios, etc.). En tercer lugar, el transporte narrativo implica un efecto emocional en el sujeto. La persona que se encuentra absorta en la narración de ficción también experimenta con más intensidad las emociones pertinentes durante el proceso de exposición o consumo del relato. Según esta teoría los tres procesos darían cuenta del estado de transporte narrativo y, este a su vez, conducirá a cambios en las creencias sobre el mundo social representado en la narración.

El concepto de transporte narrativo ha sido propuesto como el principal mecanismo o proceso mediador para explicar el impacto persuasivo de la ficción. Ahora bien, la teoría de referencia se aleja bastante de los modelos de procesamiento dual de la persuasión (Mayordomo, Zlobina, Igartua y Páez, 2003). Tanto desde el Modelo Heurístico-Sistemático como desde el Modelo de Probabilidad de Elaboración se concibe que la elaboración cognitiva, es decir, el grado de reflexión que tiene lugar en el sujeto cuando se expone a un mensaje persuasivo, constituye una variable mediadora central para explicar el impacto en actitudes y creencias. De este modo, en aquellas condiciones de alta implicación, el grado de reflexión o elaboración cognitiva predice un mayor impacto persuasivo cuando los argumentos del mensaje son de alta calidad. $Y$ en cambio, en esas mismas condiciones y ante un mensaje conformado con argumentos de baja calidad, la elaboración cognitiva o reflexión predice un bajo impacto persuasivo: si las personas consideran que los argumentos son peregrinos, criticarán el mensaje y por ello no se verán persuadidas por él. En este contexto, la elaboración cognitiva supone un proceso de evaluación crítica de los argumentos del mensaje persuasivo.

Las personas confrontadas con una narración de ficción, por lo general, se encuentran motivadas para implicarse y disfrutar con el relato, centrar la atención en él y, por ello, la capacidad para contra-argumentar se vería impedida o limitada desde un punto de vista cognitivo. Además, hay que tener en cuenta que las narraciones de ficción: a) incluyen argumentos pero de una manera sutil e implícita, $y, b)$ los temas contra-actitudinales pueden aparecer de forma sorpresiva a lo largo de la narración. Por ello, Green y Brock (2000) indican que una persona implicada con la narración no efectuará una reflexión profunda, sistemática o exhaustiva sobre los argumentos implícitos del relato y, precisamente por ello, se producirá el impacto persuasivo. De este modo se plantea que existe una relación negativa entre el grado de implicación con la narración o transporte y la capacidad crítica o de contra-argumentación, lo que llevaría a que las narraciones de ficción sean herramientas poderosas para hacer frente a la resistencia que habitualmente se produce ante mensajes persuasivos retóricos con una intención manifiesta por influir (Dal Cin, Zanna y Fong, 2002).

\section{Reflexiones finales}

La investigación sobre las intervenciones narrativas es un campo incipiente, a pesar de su extensa aplicación en el mundo para enfrentar problemas socio-sanitarios. Si bien se ha podido documentar que los formatos narrativos de educación-entretenimiento suelen tener un gran nivel de audiencia y también se ha podido contrastar su eficacia persuasiva, existe menor evidencia empírica sobre los mecanismos o procesos que explican la efectividad de tales inter- 
venciones (Moyer-Gusé, 2008). En este sentido, se debe efectuar un esfuerzo de clarificación conceptual que delimite claramente los aspectos definitorios de los dos procesos más relevantes en el proceso de persuasión narrativa: el transporte narrativo y la identificación con los personajes. Por un lado, existen instrumentos de medida validados para evaluar el transporte narrativo (véase Green y Brock, 2000), y una consolidada línea de investigación sobre los efectos del transporte narrativo, especialmente utilizando textos escritos en investigaciones de laboratorio. Sin embargo, en un estudio reciente se observó que dicha variable no jugaba un papel relevante a la hora de explicar los procesos de persuasión narrativa con producciones audiovisuales de educación-entretenimiento (Moyer-Gusé, 2010).

Se requieren nuevas investigaciones que contrasten empíricamente el papel del transporte narrativo con materiales audiovisuales (y no únicamente con textos escritos) y ante tópicos abiertamente contra-actitudinales o vinculados con los valores de las personas. En segundo lugar, a pesar de que el concepto de identificación con los personajes posee una larga historia en la investigación sobre entretenimiento mediático (véase, por ejemplo, Feilitzen y Linné, 1975), sin embargo no existen instrumentos de medida estandarizados con validez y fiabilidad contrastada para su evaluación y aún es escasa la investigación empírica acerca de los efectos de dicho proceso en las intervenciones de educación-entretenimiento (Cohen, 2001; Igartua, 2010). Recientemente, el estudio de Moyer-Gusé y Nabi (2010) contrastó que la identificación con los personajes de una narración dramática sobre los efectos de los embarazos no deseados provocaba una mayor percepción de vulnerabilidad, y esta a su vez se asociaba a una mayor intención de conducta de sexo seguro. Este tipo de trabajos son de vital importancia porque permiten poner al descubierto cómo logran su impacto las intervenciones narrativas de educación-entretenimiento.

\section{Referencias}

Ajzen, I. y Fishbein, M. (1980). Understanding attitudes and predicting social behavior. New Jersey: Prentice-Hall.

Bandura, A. (2004). Social cognitive theory for personal and social change by enabling media. En Singhal, A.; Cody, M.J.; Rogers, E.M. y Sabido, M. (Eds.). Entertainment-education and social change (pp. 75-96). Mahwah, NJ: Lawrence Erlbaum Associates.

Bruner, J. (1988). Realidad mental y mundos posibles. Barcelona: Gedisa.

Cohen, J. (2001). Defining identification: a theoretical look at the identification of audiences with media characters. Mass Communication and Society. Vol. 4, n 3, pp. 245-264.

Dal Cin, S.; Zanna, M. P. y Fong, G. T. (2002). Narrative persuasion and overcoming resistance. En Knowles, E. S. y Linn, J. A. (Eds.). Resistance and persuasion (pp. 175-191). Mahwah, NJ: Lawrence Erlbaum Associates.

Dixon, H. G.; Hill, D. J.; Borland, R. y Paxton, S. J. (2001). Public reaction to the portrayal of the tobacco industry in the film 'The Insider'. Tobacco Control. Vol. 10, n 3, pp. 285-291.

Feilitzen, C. V. y Linné, O. (1975). Identification with television characters. Journal of Commu- 
nication. Vol. 25, pp. 51-55.

Fishbein, M. y Cappella, J. N. (2006). The role of theory in developing effective health communications. Journal of Communication. Vol. 56 (suplemento), pp. 1-17.

Frijda, N. (1988). The laws of emotion. American Psychologist. Vol 43, nº 5, pp. 349-358.

Gerrig, R. J. (1993). Experiencing narrative worlds. On the psychological activities of reading. New Haven, CT: Yale University Press.

Green, M. C. (2006). Narratives and cancer communication. Journal of Communication. Vol. 56 (suplemento), pp. 163-183.

Green, M. C. y Brock, T. C. (2000). The role of transportation in the persuasiveness of public narratives. Journal of Personality and Social Psychology. Vol. 79, n 5, pp. 701-721.

Green, M. C. y Brock, T. C. (2002). In the mind's eye. Transportation-imagery model of narrative persuasion. En Green, M. C.; Strange, J. J. y Brock, T. C. (Eds.). Narrative impact. Social and cognitive foundations (pp. 315-341). Mahwah, NJ: Lawrence Erlbaum Associates.

Green, M. C. y Brock, T. C. (2005). Persuasiveness of narratives. En Brock, T. C. y Green, M. C. (Eds.). Persuasion. Psychological insights and perspectives (pp. 117-142). Thousand Oaks, CA: Sage ( $2^{\mathrm{a}}$ edición).

Green, M. C., Brock, T. C. y Kaufman, G. F. (2004). Understanding media enjoyment: the role of transportation into narrative worlds. Communication Theory. Vol. 14, n 4, pp. 311-327.

Green, M. C.; Garst, J. y Brock, T. C. (2004). The power of fiction: determinants and boundaries. En Shrum, L. J. (Ed.). The psychology of entertainment media. Blurring the lines between entertainment and persuasion (pp. 161-176). Mahwah, NJ: Lawrence Erbaum Associates.

Green, M. C.; Strange, J. J. y Brock, T. C. (2002). Narrative impact. Social and cognitive foundations. Mahwah, $\mathrm{NJ}$ : Lawrence Erlbaum Associates.

Greenberg, B. S.; Salmon, C. T.; Patel, D.; Beck, V. y Cole, G. (2004). Evolution of an E-E research agenda. En Singhal, A.; Cody, M. J.; Rogers, E. M. y Sabido, M. (Eds.). Entertainmenteducation and social change (pp. 191-206). Mahwah, NJ: Lawrence Erlbaum Associates.

Igartua, J. J. (2007). Persuasión narrativa. Alicante: Editorial Club Universitario.

Igartua, J. J. (2010). Identification with characters and narrative persuasion through fictional feature films. Communications. The European Journal of Communication Research. Vol. 35, $\mathrm{n}^{\circ} 4$, pp. 347-373.

Igartua, J. J.; Acosta, T. y Frutos, F. J. (2009). Recepción en impacto del drama cinematográfico: el papel de la identificación con los personajes y la empatía. Global Media Journal Edición Iberoamericana. Vol. $6, \mathrm{n}^{\circ} 11, \mathrm{pp} .1-18$.

Igartua, J. J.; Cheng, L. y Lopes, O. (2003). To think or not to think: two pathways towards persuasion by short films on Aids prevention. Journal of Health Communication. Vol. 8, $\mathrm{n}^{\circ} 6, \mathrm{pp}$. 513-528.

Igartua, J. J. y Muñiz, C. (2008). Identificación con los personajes y disfrute ante largometrajes de ficción. Una investigación empírica. Comunicación y Sociedad. Vol. 21, nº 1, pp. 25-52.

Lapinski, M. K. y Nwulu, P. (2008). Can a short film impact hiv-related risk and stigma perceptions? 
Results from an experiment in Abuja, Nigeria. Health Communication. Vol. 23, pp. 403-412.

Mayordomo, S.; Zlobina, A.; Igartua, J. J. y Páez, D. (2003). Persuasión y cambio de actitudes. En Páez, D.; Fernández, I.; Ubillos, S. y Zubieta, E. (Eds.). Psicología social, cultura y educación (pp. 341-363). Madrid: Pearson-Prentice Hall.

Morgan, M. (2010). Cultivation analysis and media effects. En Nabi, R. L. y Oliver, M. B. (Eds.). The Sage handbook of media processes and effects (pp. 69-82). Thousand Oaks, CA: Sage.

Morgan, S. E.; Movius, L. y Cody, M. J. (2009). The power of narratives: the effect of entertainment television organ donation storylines on the attitudes, knowledge, and behaviors of donors and nondonors. Journal of Communication. Vol. 59, n 1, pp. 135-151.

Moyer-Gusé, E. (2008). Toward a theory of entertainment persuasion: explaining the persuasive effects of entertainment-education messages. Communication Theory. Vol. 18, n 3, pp. 407425.

Moyer-Gusé, E. y Nabi, R. L. (2010). Explaining the effects of narrative in an entertainment television program: overcoming resistance to persuasion. Human Communication Research. Vol $36, n^{\circ} 1$, pp. 26-52.

Nell, V. (1988). Lost in a book. The psychology of reading for pleasure. New Haven, CT: Yale University Press.

Oatley, K. (2002). Emotions and the story worlds of fiction. En Green, M. C.; Strange, J. J. y Brock, T. C. (Eds.). Narrative impact. Social and cognitive foundations (pp. 39-69). Mahwah, NJ: Lawrence Erlbaum Associates.

Petraglia, J. (2007). Narrative intervention in behavior and public health. Journal of Health Communication. Vol. 12, pp. 493-505.

Petty, R. E.; Briñol, P. y Priester, J. R. (2009). Mass media attitude change: implications of the Elaboration Likelihood Model of persuasion. En Bryant, J.y Oliver, M. B. (Eds.). Media effects. Advances in theory and research (p. 125-164). Nueva York, NY: Routledge ( $3^{\text {a }}$ edición).

Petty, R. E. y Cacioppo, J. T. (1986). Communication and persuasion. Central and peripherical routes to attitude change. Nueva York, NY: Springer-Verlag.

Piotrow, P. T. y de Fossard, E. (2004). Entertainment-education as a public health intervention. En Singhal, A.; Cody, M. J.; Rogers, E. M. y Sabido, M. (Eds.). Entertainment-education and social change (pp. 39-60). Mahwah, NJ: Lawrence Erlbaum Associates.

Poindexter, D. (2004). A history of entertainment-education, 1958-2000. En Singhal, A.; Cody, M. J.; Rogers, E. M. y Sabido, M. (Eds.). Entertainment-education and social change (pp. 2137). Mahwah, NJ: Lawrence Erlbaum Associates.

Rice, R. E. y Atkin, C. K. (2009). Public communication campaigns: theoretical principles and practical applications. En Bryant, J. y Oliver, M. B. Media effects. Advances in theory and research (pp. 436-468). Nueva York, NY: Routledge (3ª edición).

Sabido, M. (2004). The origins of entertainment-education. En Singhal, A.; Cody, M. J.; Rogers, E. M. y Sabido, M. (Eds.). Entertainment-education and social change (pp. 61-74). Mahwah, $\mathrm{NJ}$ : Lawrence Erlbaum Associates. 
Shanahan, J. y Morgan, M. (1999). Television and its viewers. Cultivation theory and research. Cambridge: Cambridge University Press.

Singhal, A.; Cody, M. J.; Rogers, E. M. y Sabido, M. (2004). Entertainment-education and social change. History, research and practice. Mahwah, NJ: Lawrence Erlbaum Associates.

Singhal, A. y Rogers, E. M. (1999). Entertainment-education. A communication strategy for social change. Mahwah, NJ: Lawrence Erlbaum Associates.

Singhal, A. y Rogers, E. M. (2002). A theoretical agenda for entertainment-education. Communication Theory. Vol. 12, $\mathrm{n}^{\circ}$ 2, pp. 117-135.

Slater, M. D. (2002). Entertainment education and the persuasive impact of narratives. En Green, M. C.; Strange, J. J. y Brock, T. C. (Eds.). Narrative impact. Social and cognitive foundations (pp. 157-181). Mahwah, NJ: Lawrence Erlbaum Associates.

Slater, M. D. y Rouner, D. (2002). Entertainment-education and elaboration likelihood: understanding the processing of narrative persuasion. Communication Theory. Vol. 12, n² 2, pp. 173-191.

Snyder, L. B. y Rouse, R. A. (1995). The media can have more than an impersonal impact: the case of AIDS risk perception and behaviour. Health Communication. Vol. 7, pp. 125-145.

Sood, S.; Menard, T. y Witte, K. (2004). The theory behind entertainment-education programs. En Singhal, A.; Cody, M. J.; Rogers, E. M. y Sabido, M. (Eds.). Entertainment-education and social change (pp. 117-149). Mahwah, NJ: Lawrence Erlbaum Associates.

Tan, E. S. (1996). Emotion and the structure of narrative film. Film as an emotion machine. Mahwah, NJ: Lawrence Erlbaum Associates.

Usdin, S.; Singhal, A.; Shongwe, T.; Goldstein, S. y Shabalala, A. (2004). No short cuts in entertainment-education: designing Soul City step-by-step. En Singhal, A.; Cody, M. J.; Rogers, E. M. y Sabido, M. (Eds.). Entertainment-education and social change (pp. 153-175). Mahwah, NJ: Lawrence Erlbaum Associates.

Viswanath, K.; Wallington, S. F. y Blake, K. D. (2010). Media effects and population health. En R. L. Nabi y M. B. Oliver (Eds.). The Sage handbook of media processes and effects (pp. 313344). Thousand Oaks, CA: Sage. 